\title{
Triptolide Induces hepatotoxicity via inhibition of CYP450s in Rat liver microsomes
}

\author{
Yan Lu ${ }^{1,2 \dagger}$, Tong Xie ${ }^{1 \dagger}$, Yajie Zhang ${ }^{2}$, Fuqiong Zhou ${ }^{2}$, Jie Ruan², Weina Zhu², Huaxu Zhu ${ }^{3}$, Zhe Feng ${ }^{1}$ \\ and Xueping Zhou ${ }^{\text {* }}$
}

\begin{abstract}
Background: Triptolide (TP), an active constituent of Tripterygium wilfordii, possesses numerous pharmacological activities. However, its effects on cytochrome P450 enzymes (CYP450s) in rats remain unexplored.

Methods: In this study, the effects of triptolide on the six main CYP450 isoforms (1A2, 2C9, 2C19, 2D6, 2E1, and 3A) were investigated both in vivo and in vitro. We monitored the body weight, survival proportions, liver index, changes in pathology, and biochemical index upon TP administration, in vivo. Using a cocktail probe of CYP450 isoform-specific substrates and their metabolites, we then carried out in vitro enzymatic studies in liver microsomal incubation systems via ultra-high performance liquid chromatography-tandem mass spectrometry (UHPLC-MS/MS). Finally, we verified our results at the messenger ribonucleic acid (mRNA) and protein level through quantitative real-time polymerase chain reaction (RT-qPCR), western blotting, and immunohistochemical detection.
\end{abstract}

Results: The in vivo toxicity study confirmed that Sprague-Dawley (SD) rats exhibited dose-dependent hepatotoxicity after intragastric administration of TP [200, 400, and $600 \mu \mathrm{g} /(\mathrm{kg}$.day)] for 28 days. In case of the CYP450 isoforms 3A, 2C9, 2C19, and 2E1, the in vitro metabolic study demonstrated a decrease in the substrate metabolic rate, metabolite production rate, and Vmax, with an increase in the Km value, compared with that observed in the control group. Additionally, a TP dose-dependent decrease in the mRNA levels was observed in the four major isoforms of CYP3A subfamily (3A1/3A23, 3A2, 3A9, and 3A62) and CYP2C9. A similar effect was also observed with respect to the protein levels of CYP2C19 and CYP2E1.

Conclusions: This study suggests that TP can cause hepatotoxicity by reducing the substrate affinity, activity, and expression at the transcriptional and protein levels of the CYP450 isoforms 3A, 2C9,2C19, and 2E1. TP also has the potential to cause pharmacokinetic drug interactions when co-administered with drugs metabolized by these four isoforms. However, further clinical studies are needed to evaluate the significance of this interaction.

Keywords: CYP450s, Hepatotoxicity, Microsomes, Triptolide

\section{Background}

Triptolide (TP) (Fig. 1a) is a major bioactive diterpenoid isolated from the traditional Chinese medicinal herb Tripterygium wilfordii Hook $F$ (TWHF). It shows promising anti-inflammatory, immunomodulatory, antiproliferative, proapoptotic, and neuroprotective activities

\footnotetext{
* Correspondence: zxp@njutcm.edu.cn

${ }^{\dagger}$ Equal contributors

${ }^{1}$ The First Clinical College, Nanjing University of Chinese Medicine, Nanjing, Jiangsu, China

Full list of author information is available at the end of the article
}

[1-6]. However, its clinical application is limited owing to acute and chronic side effects induced in multiple organs. According to the China Food and Drug Administration (CFDA), commercial preparations of T. wilfordii were responsible for 633 adverse reaction cases from 2004 to 2011 September, including 53 severe cases that involved reproductive toxicity, hepatotoxicity, and renal cytotoxicity among other outcomes [7]. The mechanism underlying to TP-induced liver injury is caused by many reasons. In L-02 cells, TP decreased mitochondrial membrane potential and $\mathrm{Bcl}-2$, promoted the release of 
a

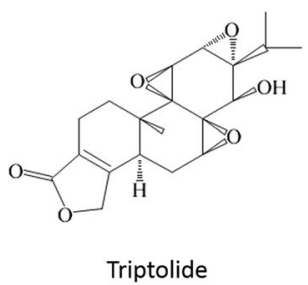

b
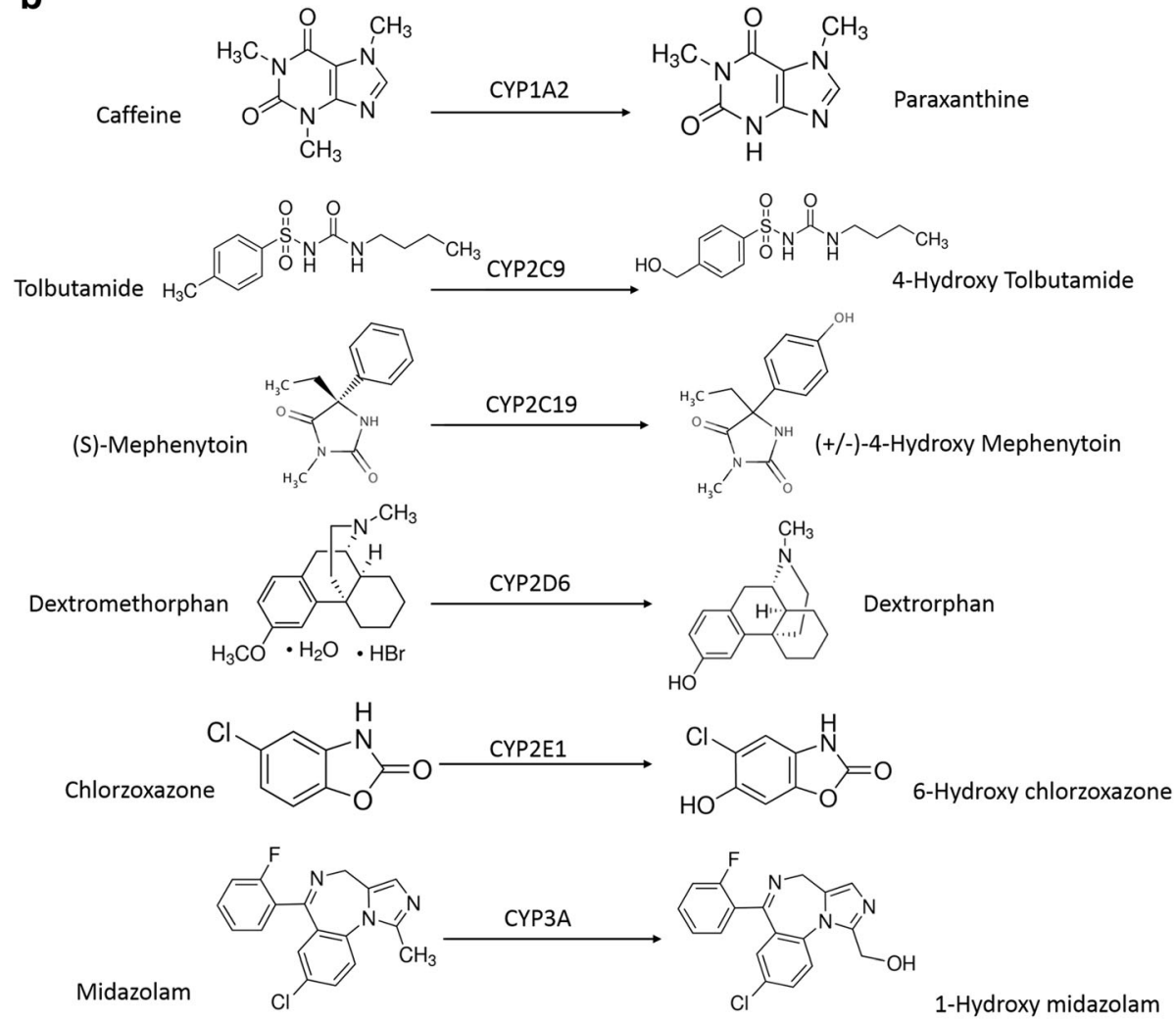<smiles>CN1C(=O)CN=C(c2ccccc2)c2cc(Cl)ccc21</smiles>

ISTD: Diazepam

Fig. 1 Related chemical structures. a The chemical structure of TP. $\mathbf{b}$ The chemical structure of the cocktail probe

cytochrome c, and up-regulated the expression of Bax, P53 and caspase 3 via the mitochondrial apoptotic pathway [8]. It was also reported that TP treatment significantly increased ROS levels and decreased GSH levels, decreased the protein expression of Nrf2 and its target genes including HO-1 and MRP2 except NQO [9]. Recent research also indicates the abnormal metabolism of Cytochrome P450s (CYP450s) enzyme system plays an important role.

Drug-induced toxicity is caused either by the parent compounds or by their reactive metabolites generated primarily through biotransformation in the liver [10]. CYP450s, a monooxygenase family with comprehensive detoxification, which play a dominant role in the redox metabolism of numerous endobiotics [11] and xenobiotics [12], are closely associated with the toxic effects of TP $[13,14]$. According to a previous study, TP was absorbed, distributed, and monohydroxylated rapidly in the liver after oral administration [15]. Further, in vitro data indicated that the metabolism of TP was mediated by both CYP3A4 and CYP2C19 [16]. Additionally, dexamethasone, a CYP3A agonist, was observed to markedly 
accelerate the metabolism of TP and thus attenuate hepatotoxicity in vivo [17]. TP is also reported to inhibit CYP3A4 expression and activity [18]. Thus, the CYP3A subfamily has been reported to play an important role in TP-induced hepatotoxicity $[18,19]$.

However, the underlying mechanisms of TP-induced toxicity mediated by the CYP450 family have not been well delineated. Since abnormal drug metabolism by CYP450s also plays an important role in the hepatotoxicity, the enzymes might trigger drug-drug interactions (DDIs) between TP and other co-administered drugs, thereby, causing the observed toxicity. In this study, we focused on understanding the role of CYP450s in mediating TP-induced hepatotoxicity. We demonstrated that TP disturbed the activity and expression of CYP450s in the liver, through UHPLC-MS/MS, RT-qPCR, and western blot analyses. We also evaluated the TP-induced in vivo hepatotoxicity using several physiological and biochemical indices. Our study focused on the six main isoforms of CYP450s: 1A2, 2C9, 2C19, 2D6, 2E1, and 3a. These six isoforms account for more than $80 \%$ of the hepatic CYP450s, and metabolize more than $90 \%$ of the clinically approved drugs [20]. The substrates, metabolites in the cocktail probe used in this study are shown in (Fig. 1b). Based on the results obtained, we concluded that CYP3A, CYP2C9, CYP2C19, and CYP2E1 were the CYP450 subfamily members most affected by TP.

\section{Methods}

\section{Chemicals and reagents}

TP (CAS No. 38748-32-2), tolbutamide (D860), midazolam (MDZ), chlorzoxazone (CLZ), caffeine (CAF), paraxanthine, 4-hydroxytolbutamide, \pm--4 -hydroxymephenytoin, dextrorphan, 1-hydroxymidazolam, diazepam, $\mathrm{NADPH}$, D-glucose-6-phosphate disodium salt, and glucose-6-phosphate dehydrogenase were purchased from Sigma-Aldrich (St. Louis, MO, USA). S-mephenytoin (MT) and 6-hydroxychlorzoxazone were purchased from Santa Cruz Biotechnology (Santa Cruz, CA, USA). Dextromethorphan (DM) was obtained from the National Institute for the Control of Pharmaceutical and Biological Products (Beijing, China). High-performance liquid chromatographygrade acetonitrile, methanol, formic acid, and ethyl acetate were obtained from Merck (Darmstadt, Germany). Deionized water was obtained using a Milli-Q ${ }^{\circ}$ system (Millipore Corporation, Billerica, MA). Quantitative detection kits for Alanine aminotransferase (ALT), aspartate aminotransferase (AST)、 total protein (Tp)、globulin(GLB)、 albumin(ALB)、 triglycerides (TG)、 total cholesterol (Tchol), and glucose (Glu) were obtained in Beijing Leadman Biochemistry Technology Co. Ltd (Beijing China). Carbon monoxide was obtained from Nanjing Weichuang Gas Co. Ltd. (Nanjing, China). Radioimmunoprecipitation assay buffer, phenylmethanesulfonyl fluoride (PMSF), and sodium dodecyl sulfate-polyacrylamide gel electrophoresis (SDS-PAGE) sample loading buffer were purchased from Beyotime Institute of Biotechnology (Jiangsu, China). Polyvinylidene difluoride (PVDF) membranes were obtained from Millipore (Shanghai, China). Rabbit anti-rat CYP2C19 polyclonal antibody and rabbit anti-rat CYP2E1 polyclonal antibody were purchased from Abcam (Cambridge, MA, USA). The bicinchoninic acid (BCA) protein assay kit was purchased from Thermo Fisher Scientific (Waltham, MA, USA). All other chemicals and solvents used were of analytical grade.

\section{Animals and experimental design}

Since the toxic effects of TP are significantly different between different sexes [21], we specifically chose female SD rats for our study. All animal studies were performed with the approval of the Institutional Animal Care and Use Committee of Nanjing University of Chinese Medicine, and were performed according to the guidelines of the National Institutes of Health for the Care and Use of Laboratory Animals (NIH publication No. 80-23). Female SD rats (180-220 g) were purchased from the Charles River Experimental Animal Company (Beijing, China). All rats were housed in an air-conditioned animal quarter at a temperature of $23-27^{\circ} \mathrm{C}$ and a relative humidity of $45-55 \%$, with ad libitum access to water and food. The animals were acclimatized to the facilities for a week and then fasted, with free access to water for $12 \mathrm{~h}$ prior to each experiment. The rats were randomly divided into four groups of 12 animals each. While the control group rats received the vehicle alone, the three TP group rats received different concentrations of TP (200 $\mu \mathrm{g} /(\mathrm{kg}$.day), $400 \mu \mathrm{g} /(\mathrm{kg}$.day), and $600 \mu \mathrm{g} /(\mathrm{kg}$.day), once daily for 28 days. During the experiment, the rats were generally monitored on a daily basis and their body weights were measured weekly. After the final drug administration, the rats were fasted overnight, anesthetized with $10 \%$ chloral hydrate $(0.35 \mathrm{~mL} / 100 \mathrm{~g})$ by intraperitoneal injection, and then sacrificed. Blood samples were drawn and the livers were collected for further analysis.

\section{In vivo toxicity study}

The liver samples were immediately weighed for liver index calculation (liver weight $\times 100 \%$ /body weight) and frozen in liquid nitrogen. Abdominal aortic blood was drawn and centrifuged at $3000 \mathrm{rpm}$ for $5 \mathrm{~min}\left(4^{\circ} \mathrm{C}\right)$ to collect the blood serum for the determination of ALT, AST, Tp, ALB, TG, T-chol, and GLU levels by using an automatic biochemistry analyzer (LX20, Beckman Coulter Inc., Miami, FL, USA). Slices of the same part of the livers were cut and fixed in phosphate-buffered $10 \%$ formaldehyde solution and then embedded in paraffin wax. Sections of liver tissue were cut and stained with hematoxylin and eosin and examined for histopathological changes 
under an Olympus DX45 microscope (Olympus Corporation, Tokyo, Japan). The images were taken using an Olympus DP72 camera (Olympus Corporation, Tokyo, Japan) at an original magnification of $200 \times$.

\section{In vitro metabolic study}

\section{Preparation and appraisal of rat liver microsomes}

Rat liver microsomes were obtained via differential centrifugation [22] (L-80XP, Microfuge $e^{\bullet}$ 16, Beckman Coulter Inc., Miami, FL, USA). The microsomes were stored in buffer [10 mM Tris-acetate, $1 \mathrm{mM}$ ethylenediaminetetraacetic acid (EDTA), $100 \mathrm{mM}$ PMSF, and 20\% glycerol, pH: 7.4] at $-80{ }^{\circ} \mathrm{C}$ until further use. Protein concentrations were determined by the BCA method and CYP450 content was determined by the method of Omura and Sato [23].

\section{Study of CYP450 activity in in vitro microsomal incubation systems}

The enzymatic activities of $\mathrm{P} 450$ isoforms were characterized based on the reactions shown in (Fig. 1b). The microsomal incubation system $(200 \mu \mathrm{L})$ consisted of a buffer [10\% sucrose, $100 \mathrm{mM}$ EDTA, $1 \mathrm{mM}$ PMSF, $2 \mathrm{mM}$ dithiothreitol (DTT), and $100 \mathrm{mM}$ phosphate-buffered saline (PBS), pH 7.4], an NADPH regeneration system (0.2 mM NADP+, 2 mM glucose-6-phosphate, and 0.4 IU glucose6-phosphate dehydrogenase), hepatic microsomes [0.5 mg (protein) $/ \mathrm{mL}$ ], an inhibitor, and a cocktail probe (CAF/ D860/MT/DM/CLZ/MDZ: 15/20/10/10/5/2.5 $\mu$ M) [24].

After pre-incubation in a shaking incubator block (Eppendorf Thermomixer 5436, Hamburg, Germany) for $5 \mathrm{~min}$ at $37{ }^{\circ} \mathrm{C}$ the reaction was initiated by adding $\mathrm{NADP}+(0.2 \mathrm{mM})$. The reactions were performed at $37^{\circ}$ $\mathrm{C}$ for $30 \mathrm{~min}$ and terminated by the addition of $200 \mu \mathrm{L}$ of ice-cold methanol - acetonitrile (1: $1, \mathrm{~V}: \mathrm{V})$ solution, which contained Diazepam $(8 \mu \mathrm{g} / \mathrm{mL})$ as an internal standard (ISTD). The mixtures were immediately cooled in an ice bath to precipitate the proteins, then shaken and centrifuged for $10 \mathrm{~min}$ at $12000 \mathrm{rpm}$. An aliquot of $20 \mu \mathrm{L}$ of the supernatant was injected for UHPLC-MS/ MS analysis to test the final concentration of substrates and metabolites. The substrate metabolic rate (\%) and the production of the metabolites $[\mathrm{nmol} /($ protein $\mathrm{g} \times$ min)] was used as the enzyme activity index.

To estimate the kinetic parameters, the microsomes were incubated with different concentrations of the cocktail probe (diluted by half dilution method as listed in Table 1). The concentration of each metabolite was determined by UHPLC-MS/MS at different timepoints $(1,2,4,6$, and $10 \mathrm{~min})$ and the metabolic rate was calculated by linear regression analysis. The Vmax and $\mathrm{Km}$ value of each CYP450 isoform was calculated by nonlinear regression analysis of experimental data according to the Michaelis-Menten model of enzyme kinetics, using the Prism 5.0 program:
Table 1 The cocktail probe of different concentration $(\mu \mathrm{M})$

\begin{tabular}{llllllll}
\hline Substrates & \multicolumn{9}{l}{ Concentration Number } \\
\cline { 2 - 8 } & 1 & 2 & 3 & 4 & 5 & 6 & 7 \\
\hline Caffeine(CAF) & 1.875 & 3.75 & 7.5 & 15 & 30 & 60 & 120 \\
Tolbutamide(D860) & 0.625 & 1.25 & 2.5 & 5 & 10 & 20 & 40 \\
(S)- Mephenytoin(MT) & 1.25 & 2.5 & 5 & 10 & 20 & 40 & 60 \\
Dextromethorphan(DM) & 2.5 & 5 & 10 & 20 & 40 & 80 & 160 \\
Chlorzoxazone(CLZ) & 1.25 & 2.5 & 5 & 10 & 20 & 40 & 60 \\
Midazolam(MDZ) & 0.313 & 0.625 & 1.25 & 2.5 & 5 & 10 & 20 \\
\hline
\end{tabular}

$$
V=\frac{V_{\max }[S]}{\left(K_{m}+[S]\right)}
$$

Where $\mathrm{V}$ is the metabolic rate; $\mathrm{Vmax}$ is the maximum velocity; $\mathrm{Km}$ is the Michaelis-Menten constant; [S] is the substrate concentration.

\section{UHPLC-MS/MS-ESI analysis}

Chromatographic separations were carried out on an Agilent 1290 UHPLC system (Agilent Technologies, Santa Clara, CA, USA) using an Agilent ZORBAX RRHD Eclipse Plus C18 column $(2.1 \times 50 \mathrm{~mm}$ inner diameter,1.8 $\mu \mathrm{m}$ particle size) (Agilent Technologies, Santa Clara, CA, USA). The elution profile was composed of an initial isocratic step with water $(0.1 \%$ formic acid): acetonitrile (ACN) (95:5) for $1.5 \mathrm{~min}$ and then increasing $\mathrm{ACN}$ to $30 \%$ over $4 \mathrm{~min}$ to separate the substrates and metabolites at $30{ }^{\circ} \mathrm{C}$. The column was washed with $90 \%$ of $\mathrm{ACN}$ for $2.5 \mathrm{~min}$ followed by the equilibration of the column for 5 min with $5 \% \mathrm{ACN}$. The flow rate was $0.4 \mathrm{~mL} / \mathrm{min}$ and the injection volume was $5 \mu \mathrm{L}$. An Agilent 6460 triple quadrupole-mass spectrometer with an electrospray ion source (Agilent Technologies, Santa Clara, CA, USA) was used for flow injection analysis with optimized fragmentor and source parameters. The optimized source parameters for MS analysis were drying gas temperature, $350{ }^{\circ} \mathrm{C}$; gas flow, $10 \mathrm{~L} / \mathrm{min}$; nebulizer gas flow pressure, $35 \mathrm{psi}$; and capillary voltage, $4500 \mathrm{~V}$.

\section{Verification of observed effects at the mRNA and protein level} Quantitative real-time polymerase chain reaction

While implementing this experiment, we realized that human CYP3A subfamily isoforms, such as CYP3A4, CYP3A43, CYP3A7, etc., have several commercially available antibodies; however, there are no such antibodies for the main CYP3A subfamily isoforms (e.g. CYP3A1, CYP3A2, etc.) and CYP2C9 of rats. In order to validate the metabolic study and further probe the specific roles of the CYP3A subfamily and CYP2C9, we measured the mRNA expression of five major CYP3A 
subfamily isoforms (CYP3A1/3A23, CYP3A2, CYP3A9, CYP3A18, and CYP3A62) [25-28] and CYP2C9 using RT-qPCR. Frozen tissue samples were homogenized in $1 \mathrm{~mL} \mathrm{Trizol}^{\circ}$ reagent and total RNA was extracted following the manufacturer's protocol. After ethanol precipitation, the vacuum-dried RNA was dissolved in $50 \mu \mathrm{L}$ nuclease-free water, and the concentration and purity of isolated RNA was determined by absorbance at $260 \mathrm{nM}$. The $260 / 280 \mathrm{nM}$ ratios of the samples were between 1.8 and 2.0. RNA purity and concentration was assessed using a NanoDrop 2000 spectrophotometer (Thermo Fisher Scientific Waltham, MA, USA). Thus, cDNA synthesis was performed at $50{ }^{\circ} \mathrm{C}$ for 60 min by adding $7 \mu \mathrm{L}$ of the RT master mix ("PrimeScriptTM RT Master Mix RR036A (TaKaRa, Tokyo, Japan)) and terminated by incubating for $15 \mathrm{~min}$ at $75{ }^{\circ} \mathrm{C}$. Distilled water was added to the reaction mixture to a final volume of $100 \mu \mathrm{L}$. Real-time qPCR was performed with an $\mathrm{ABI}^{\odot} 7500$ system (Life Technologies Corporation, Gaithersburg, MD, USA) using the 2x SYBR ${ }^{\circ}$ Select Master Mix (Thermo Fisher Scientific, Waltham, MA, USA) for the detection of PCR products. $\beta$-actin was used as an internal control. The primer pairs used were as listed in Table 2. Amplification was done with a hot start polymerase activation step for $10 \mathrm{~min}$ at $95{ }^{\circ} \mathrm{C}$, followed by 40 cycles of $15 \mathrm{~s}$ at $95^{\circ} \mathrm{C}$ and $1 \mathrm{~min}$ at $60{ }^{\circ} \mathrm{C}$, and the cycle threshold $(\mathrm{CT})$ values of the target gene were identified. All samples were run in triplicates.

\section{Western blotting}

The total protein extract was prepared by diluting $50 \mu \mathrm{L}$ liver microsome suspension with 1 volume of radioimmunoprecipitation assay (RIPA) lysis buffer (150 mM

Table 2 Primers used in RT-PCR

\begin{tabular}{lll}
\hline Target gene & Sequence of primers \\
\hline CYP3A1/3A23 & forward & TTTCCTTTGTCCTGCATTCC \\
reverse & CATAGGTGGGAGGTGCCTTA \\
CYP3A2 & forward & CGTCGATTCCCTTAACAACC \\
& reverse & AATCCTTGGGAACATGCAG \\
CYP3A9 & forward & ACAAAGACCCGCATTACTGG \\
& reverse & GCAAACCTCATGCCAATACA \\
CYP3A18 & forward & CCAATAAGGCACCTGTCACC \\
& reverse & AGGGTTCCGATGAAGAGGAT \\
CYP3A62 & forward & GATGTGGAGATTGTGGCTCA \\
& reverse & TCTGGAGATCAGGGTGTGTG \\
CYP2C9 & forward & CTGCTGCTGCTGAAACACGTG \\
& reverse & GGATGACAGCGTACTATCAC \\
B-actin & forward & TCACCCACACTGTGCCCATCTATGA \\
& reverse & CATCGGAACCGCTCATTGCCGATAG \\
\hline
\end{tabular}

$\mathrm{NaCl}, 1 \%$ Nonidet $^{\text {tix }} \mathrm{P}-40$ (NP-40), 0.5\% sodium deoxycholic acid, $0.1 \%$ SDS, and $50 \mathrm{mM}$ Tris- $\mathrm{Cl}, \mathrm{pH}$ 7.5) for $15 \mathrm{~min}$ and then centrifuging at $13,000 \mathrm{rpm} 4{ }^{\circ} \mathrm{C}$ for $10 \mathrm{~min}$. Aliquots containing $20 \mu \mathrm{g}$ of protein were separated by SDS-PAGE on a 10\% gradient gel (Invitrogen, Carlsbad, CA, USA) and transferred to a PVDF membrane which was blocked with $5 \%$ non-fat dry milk in Trisbuffered saline with Tween 20 (TBST) (200 mM Tris$\mathrm{HCl}, 1.37 \mathrm{M} \mathrm{NaCl}, 0.1 \%$ Tween 20, $\mathrm{pH} 7.6$ ) for $1 \mathrm{~h}$. The membrane was then incubated with rabbit antirat CYP2C19 polyclonal antibody (1:2000 dilution), rabbit anti-rat CYP2E1 polyclonal antibody (1:1000 dilution) and glyceraldehyde-3-phosphate dehydrogenase (GAPDH) antibody (1:2000 dilution), overnight at $4{ }^{\circ} \mathrm{C}$. After rinsing five times with TBST, for 5 min each time, at $20{ }^{\circ} \mathrm{C}$, the membrane was incubated with horseradish peroxidase (HRP)-labeled anti-rabbit immunoglobulin G (IgG) antibody (Santa Cruz Biotechnology, Santa Cruz, CA, USA). The immunoreactive bands were visualized using an enhanced chemiluminescence detection system (ChemiDoc ${ }^{\mathrm{me}}$ XRS+, Bio-Rad, Hercules, CA, USA) and quantified by densitometry using Image 1.41 (National Institutes of Health, Bethesda, Maryland, USA) software.

\section{Immunohistochemical detection}

The tissue sections were incubated with rabbit anti-rat CYP2C19 polyclonal antibody (1:200 dilution) and rabbit anti-rat CYP2E1 polyclonal antibody (1:100 dilution) in blocking solution $(0.4 \%(\mathrm{v} / \mathrm{v})$ Triton X-100 and $3 \%(\mathrm{v} / \mathrm{v})$ normal goat serum (NGS) in PBS) for $1 \mathrm{~h}$. After incubation, the slices were washed four times, for $10 \mathrm{~min}$ each time, with 0.01 M PBS. Then, the sections were again incubated for $2 \mathrm{~h}$ with anti-rabbit antibody (1:500 dilution) at room temperature. After several PBS washes, the antibody complex was detected using a modification of the ABC system (Vectastain ${ }^{\bullet} \mathrm{ABC}$ kit, Vector Laboratory Inc., Burlingame, CA, USA). The immunoreactive cells were stereologically quantified using Image-Pro Express 6 (Media Cybernetics, CA, USA) software. The selected areas were digitized with an Olympus DX45 microscope (Olympus Corporation, Tokyo, Japan). The images were taken using an Olympus DP72 camera (Olympus Corporation, Tokyo, Japan) at an original magnification of $400 \times$.

\section{Statistical analysis}

SPSS version 19.0 for Windows (IBM Corp, Armonk, NY, USA) was used for all statistical analyses. All experiments were performed at least thrice. Comparisons were made between two groups using two-sided Student's $t$ test and among multiple groups using one-way ANOVA followed by Tukey's post hoc test. Data are expressed as Mean \pm SD and $P<0.05$ was considered statistically significant. 


\section{Results}

In vivo toxicity study

\section{General observation and survival proportions}

After one-week administration of TP, the rats began to exhibit restlessness by jumping up and down. Some rats showed reduced spontaneous activity and were less responsive to outside stimulations. During the second week, the groups which were administered 400 and $600 \mu \mathrm{g} /(\mathrm{kg}$.day) of TP began showing symptoms of mortality. In the third and fourth week, the rats of the TP groups showed several symptoms of severe poisoning such as arched vertical hair, squinting or closed eyes, reduced activity, diarrhea, weight loss, and death. Of the rats that lived through the 28-day treatment period, 11 were from the $200 \mu \mathrm{g} /(\mathrm{kg}$.day) group, 8 were from the $400 \mu \mathrm{g} /(\mathrm{kg}$.day) group, and 6 were from the $600 \mu \mathrm{g} /$ (kg.day) group. The number of deaths observed during the 28 days is presented in (Fig. 2a).

\section{Effects of TP on the body weight of rats}

Before the treatment with TP, there was no significant difference in body weight among the four groups. After the 28-day treatment period, the body weight of TP-treated rats was markedly decreased $(P<0.05$ or $P<0.01)$, especially during the latest week of measurement, compared with the steadily increasing trend observed in the control group. Among the TP treated groups, the group which received with $600 \mu \mathrm{g} /(\mathrm{kg}$.day) of TP demonstrated a dramatic weight loss compared with that observed in other groups $(P<0.01)$. These experimental results are shown in (Fig. 2b).

\section{Effects of TP on the liver index of rats}

After the rats were sacrificed, the livers were placed on ice and weighed. The control group livers were dark red in color with bright red cut surfaces, soft and normal volumes, and smooth capsules. In contrast, the TP group livers were swollen with purple or dark cut surfaces. Based on the statistical analysis, there was no significant difference in liver index between the control and TPtreated groups (Fig. 2c).

\section{Effects of TP on hepatic histopathology}

Microscopically, the control group showed no major remarkable pathological changes. After the oral administration of TP for $(200,400$, and $600 \mu \mathrm{g} /(\mathrm{kg} /$. day $)$ ) for 28 days, the rats showed significant histopathological changes, mainly including apparent liver cell degeneration of liver cell and inflammatory cell infiltration of inflammatory cells in the hepatic lobules and portal area, as shown in (Fig. 2d-g).

\section{Effects of TP on biochemical indicators}

As shown in Fig. 3, after the oral administration of either the vehicle or TP $(200,400$, and $600 \mu \mathrm{g} /(\mathrm{kg}$.day $))$ for 28 days, significant increase $(P<0.05$ or $P<0.01)$ in the

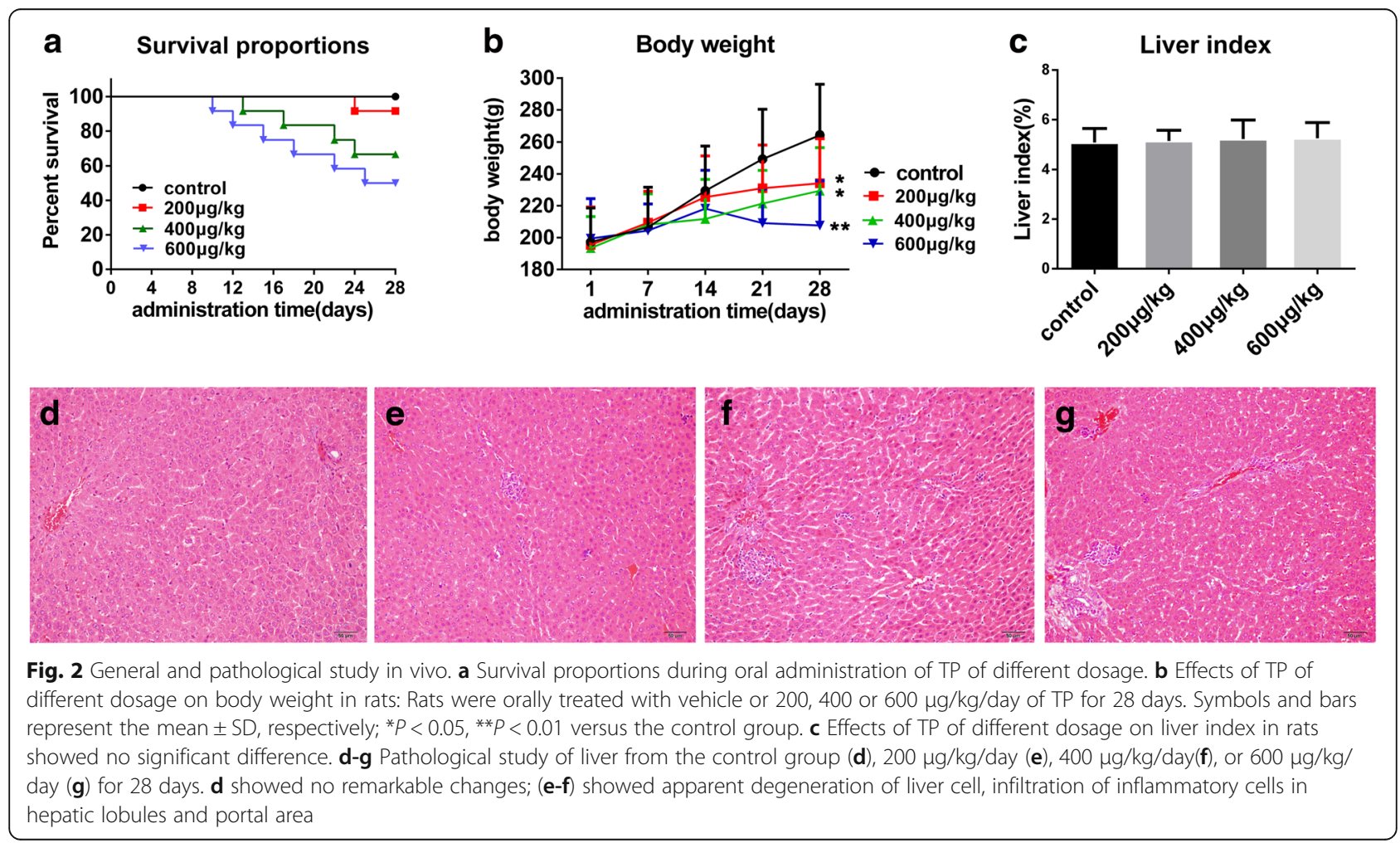




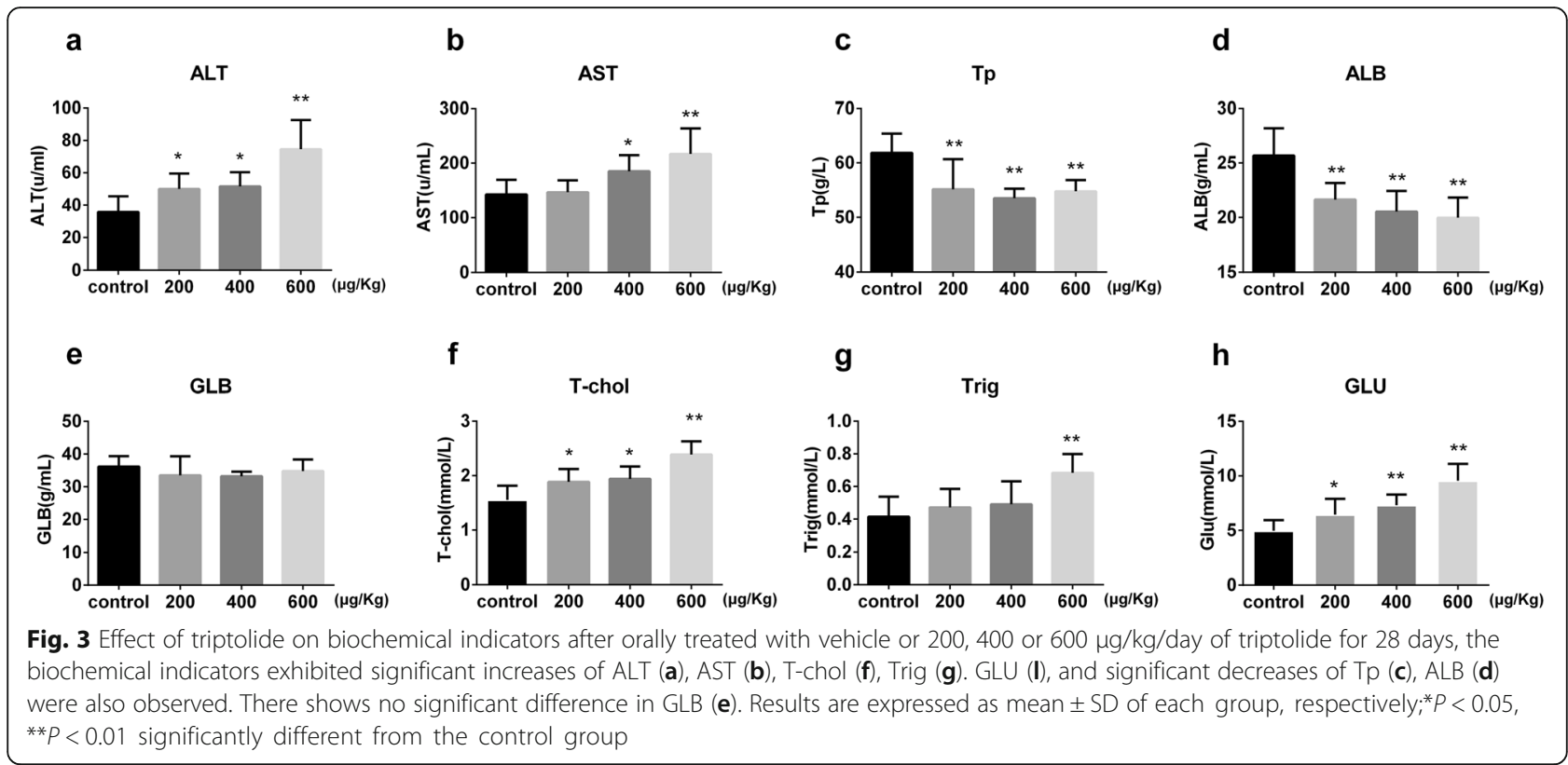

levels of ALT, AST, T-chol, Trig, and GLU and significant decrease $(P<0.05$ or $P<0.01)$ in the levels of Tp and ALB were observed in the TP groups in comparison with that observed in the control group. Thus, most of the biochemical indicators changed in a TP dosagedependent manner compared with the observed values in the control group. However, there was no significant difference in GLB levels (see Additional file 1).

\section{In vitro metabolic study}

\section{Effects of TP on rat liver microsomes}

No significant difference in microsomal protein concentration was observed in TP group when compared to that in the control group (Fig. 4a). However, TP treatment caused a significant decrease $(P<0.01)$ in the microsomal CYP450 content (Fig. 4b), with the $400 \mu \mathrm{g} /$ (kg.day) dose group exhibiting maximal suppression (58.3\%) of CYP450 content.

\section{Chromatography-mass behavior and specificity study}

Since our initial efforts were focused on monitoring the changes in CYP450 content upon oral administration of TP, we explored whether the six main CYP450 isoformspecific substrates and their metabolites were suitable for use in cocktail incubations. We thus established a cocktail assay for simultaneous determination of the activities of six main CYP450 isoforms in liver microsomes using UHPLC-MS/MS, with a cocktail probe consisting of the isoform-specific substrates, metabolites, and an internal standard. The multiple reaction monitoring (MRM) transitions, optimized fragmentor voltage, collision energy, and selected reaction monitoring (SRM) pairs of
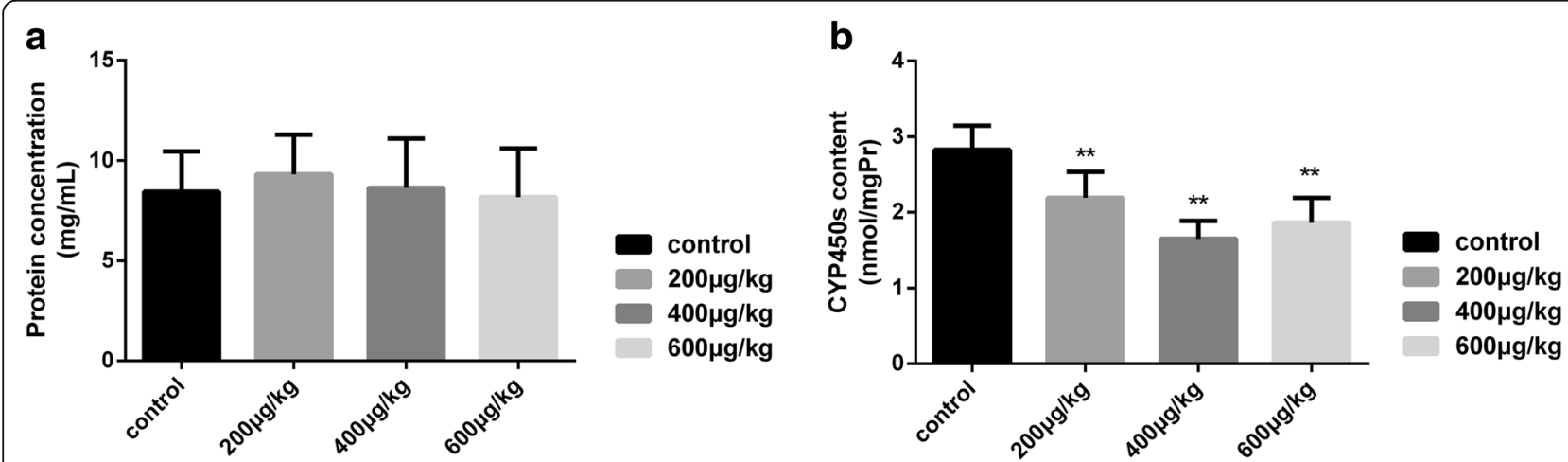

Fig. 4 The effects of protein concentrations and CYP450s content of liver microsomes. a Effects of TP on the microsomal protein concentration showed no significant difference. b CYP450s content of liver microsomes showed a significant decrease $(P<0.01)$ after the TP administration of all the different dosages. Results are expressed as mean \pm SD of each group, respectively; ${ }^{*} P<0.05,{ }^{* *} P<0.01$ significantly different from the control group 
Table 3 MRM chromatogram by UHPLC/MIS/MS method for each subject from a normal assay sample

\begin{tabular}{|c|c|c|c|c|c|c|}
\hline component & Corresponding CYP450s & parent ion & daughter ion & Fragmentor $\mathrm{N}$ & Collision energy $N$ & polarity \\
\hline Caffeine(CAF) & CYP1A2 & 195.0 & 137.8 & 100 & 20 & ESI+ \\
\hline Tolbutamide(D860) & CYP2C9 & 269.1 & 169.8 & 110 & 13 & ESI- \\
\hline (S)-Mephenytoin(MT) & CYP2C19 & 219.0 & 134.0 & 100 & 17 & ESI+ \\
\hline Dextromethorphan(DM) & CYP2D6 & 272.0 & 214.9 & 155 & 25 & ESI+ \\
\hline Chlorzoxazone(CLZ) & CYP2E1 & 168.0 & 131.8 & 120 & 17 & ESI- \\
\hline Midazolam(MDZ) & CYP3A & 326.0 & 291.0 & 106 & 25 & ESI+ \\
\hline Paraxanthine & CYP1A2 & 181.0 & 123.9 & 120 & 21 & ESI+ \\
\hline 4-Hydroxy Tolbutamide & CYP2C9 & 287.0 & 74.2 & 95 & 13 & ESI+ \\
\hline (+/-)-4-Hydroxy Mephenytoin & CYP2C19 & 235.0 & 150.0 & 90 & 17 & ESI+ \\
\hline Dextrorphan & CYP2D6 & 258.2 & 157.0 & 145. & 40 & ESI+ \\
\hline 6-Hydroxy chlorzoxazone & CYP2E1 & 183.9 & 64.1 & 100 & 33 & ESI- \\
\hline 1-Hydroxymidazolam & CYP3A & 342.0 & 324 & 162 & 21 & $\mathrm{ESI}+$ \\
\hline Diazepam(DZP) & ISTD & 285.0 & 193.0 & 159 & 33 & ESI+ \\
\hline
\end{tabular}

each substrate and its metabolite are reported in Table 3. The specificity of the tandem mass spectrometer allowed a fast liquid chromatography gradient to be employed. Representative chromatograms for substrates and metabolites in the microsomal incubation mixtures are presented in Fig. 5. There was no interference from other substrates or metabolites at any of the retention times of interest for any metabolite MRM channel.

Stability tests showed that samples remained stable even after being placed at room temperature for $24 \mathrm{~h}$ and being subjected to three repeated freeze-thaw cycles. In the precision test, the average standard deviation of three substances corresponding to the peak area was < $5 \%$. The recovery rate test showed that both the absolute and method recovery rates were $>90 \%$.

\section{Effects of TP on the substrates and metabolites of CYP450 enzymes}

In this study we determined the enzyme activity index in terms of the substrate metabolic rate and the metabolite production rate $[\mathrm{nmol} /($ protein $\mathrm{g} \times \mathrm{min})]$. After oral administration of either the vehicle or TP $(200,400$ or $600 \mu \mathrm{g} /(\mathrm{kg}$. day $))$ for 28 days, the liver microsomes were incubated with the cocktail probe (CAF/D860/MT/DM/ CLZ/MDZ: $15 / 20 / 10 / 10 / 5 / 2.5 \mu \mathrm{M})$ for $30 \mathrm{~min}$. The final concentrations of the substrates and metabolites were detected by UHPLC-MS/MS. Although the metabolic rates of CYP1A2 and CYP2D6 remained the same, the rates of other CYP450s showed significant changes $(P<0.05$ or $P<0.01)$ in TP-treated groups than in the control group (Fig. 6a). While the metabolic rates of CYP2C19 (71.3\%) and CYP3A (40.2\%) decreased in the $200 \mu \mathrm{g} /$ (kg.day) TP group, the rates of CYP2C19 (58.1\%), CYP3A (35.4\%), CYP2E1 (77.2\%), and CYP2C9 (64.6\%) were decreased in the $400 \mu \mathrm{g} /(\mathrm{kg}$.day) TP group. Similarly, the
$600 \mu \mathrm{g} /(\mathrm{kg}$.day) TP group showed a more dramatic decrease in the rates of CYP2C19 (41.1\%), CYP3A (31.6\%), CYP2E1 (75.9\%), and CYP2C9 (51.1\%). Similar decreases $(P<0.05$ or $P<0.01)$ were also seen in the metabolite production rates in TP-treated groups in comparison with that observed in the control group (Fig. 6b). While the metabolite production rates of CYP2C19 (70.1\%) and CYP3A (40.2\%) decreased in the $200 \mu \mathrm{g} /(\mathrm{kg}$.day) $\mathrm{TP}$ group, the rates of CYP2C19 (58.1\%), CYP3A (35.4\%), CYP2E1 (66.7\%), and CYP2C9 (28.1\%) decreased in the $400 \mu \mathrm{g} /(\mathrm{kg}$.day) TP group. The $600 \mu \mathrm{g} /(\mathrm{kg}$.day) TP group showed a more dramatic decrease in the metabolite production rates of CYP2C19 (41.1\%), CYP3A (31.6\%), CYP2E1 (39.8\%), and CYP2C9 (27.4\%) (See Additional file 2).

Thus, when compared with the control group, 28-day $\mathrm{TP}$ administration inhibited either the substrate reduction or metabolite production. Further, decrease in the activities of CYP450s became more pronounced with the increase in TP dosage.

\section{Effects of TP on the kinetic parameters of CYP450 family}

In this study, we observed the production of the metabolites $[\mathrm{nmol} /($ protein $\mathrm{g} \times \mathrm{min})]$ by incubating the microsomes with different concentrations of the substrates. The Km and Vmax values of each CYP450 isoform were calculated by non-linear regression analysis of experimental data according to the Michaelis-Menten model of enzyme kinetics, using the Prism 5.0 program. As shown in Fig. 7, after oral administration of either the vehicle or TP $(200,400$ or $600 \mu \mathrm{g} /(\mathrm{kg}$.day $))$ for 28 days, the liver microsomes were incubated with different concentrations of the cocktail probe (CAF/D860/MT/DM/ CLZ/MDZ) for $1,2,4,6$, and $10 \mathrm{~min}$. In the TP-treated groups, the $\mathrm{Km}$ values of CYP1A2 and CYP2D6 remained the same while the corresponding values of 


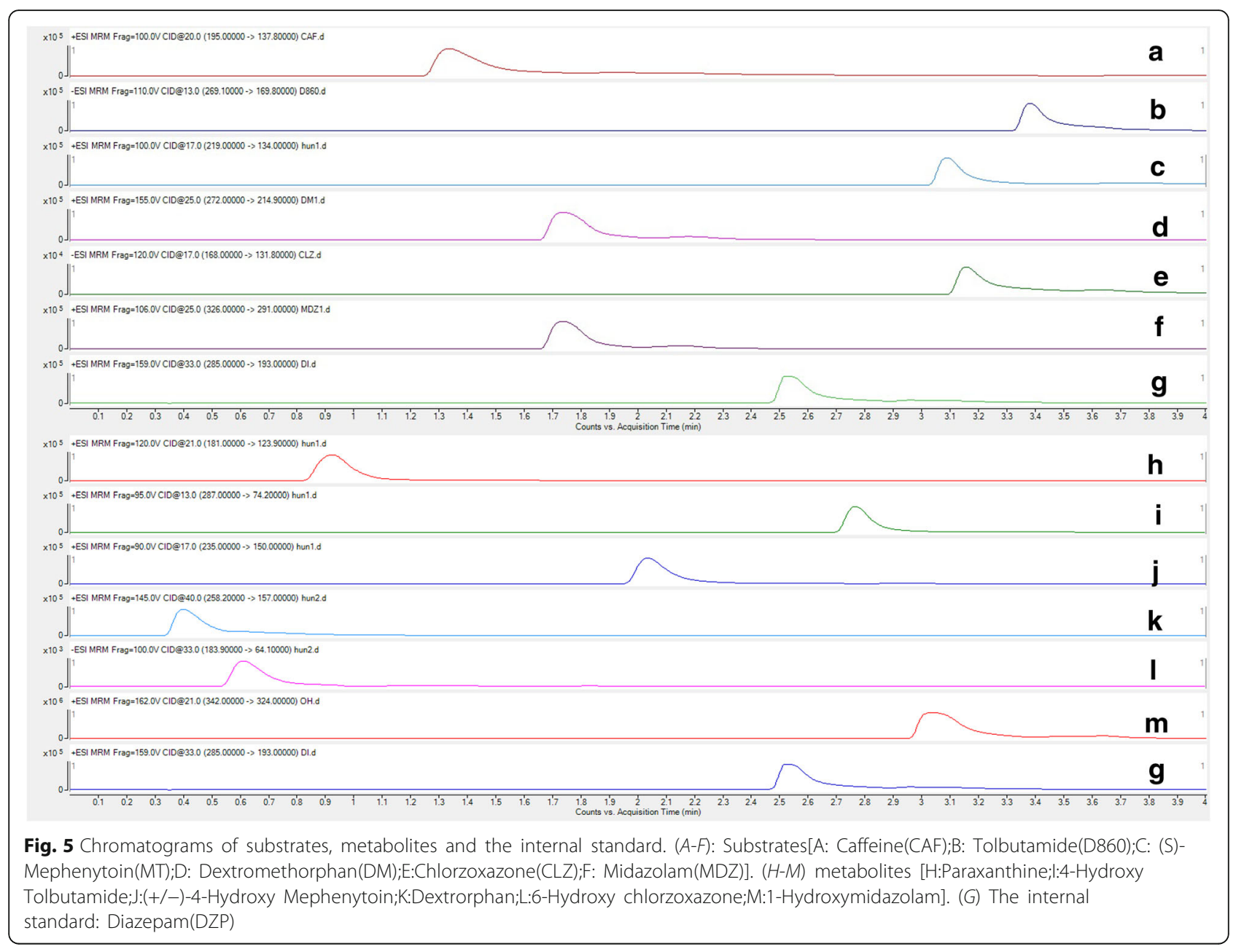

other CYP450s showed significant changes $(P<0.05$ or $P<0.01)$, in comparison with the control group values. The $200 \mu \mathrm{g} /(\mathrm{kg}$.day) TP group exhibited an increase in the $\mathrm{Km}$ values of CYP2C19 (1.31 fold) and CYP3A (1.23 fold). Similarly, the $400 \mu \mathrm{g} /(\mathrm{kg}$.day) TP group exhibited an increase in the Km values of CYP2C19 (1.30 fold), CYP3A (1.78 fold), CYP2E1 (1.45 fold), and CYP2C9 (1.59 fold). The $600 \mu \mathrm{g} /(\mathrm{kg}$.day) TP group showed a more dramatic increase in the $\mathrm{Km}$ values of CYP2C9 (1.91 fold), CYP3A (2.08 fold), CYP2E1 (1.47 fold), and CYP2C19 (1.33 fold). The metabolite production rates followed a decreasing trend $(P<0.05$ or $P<0.01)$ in the TP-treated groups in comparison to that observed in the control groups. While the metabolite production rates of CYP2C19 (87.8\%) and CYP3A (58.8\%) were decreased in the $200 \mu \mathrm{g} /(\mathrm{kg}$.day) TP group, the rates of CYP2C19 (68.7\%), CYP3A (77.5\%), and CYP2C9 (75.4\%) were decreased in the $400 \mu \mathrm{g} /(\mathrm{kg}$.day) TP group. The $600 \mu \mathrm{g} /$ (kg.day) TP group showed a more dramatic decrease in the metabolite production rates of CYP2C19 (60.9\%), CYP3A (65.7\%), CYP2C9 (60.0\%), and CYP2E1 (85.9\%) (see Additional file 3).
The $\mathrm{Km}$ value represents the affinity of a CYP450 enzyme for its specific substrate while the Vmax value represents the theoretical maximum metabolic rate of the substrate in the incubation system. These two parameters are very important indicators in the study of the kinetics of enzyme-catalyzed reactions. In comparison with the $\mathrm{Km}$ and Vmax value trends of CYP450s in the control groups, the trends observed in the TP-treated groups after the 28-day treatment period reflected the inhibitory effects of TP on CYP450 activity. Further, this TP-induced inhibition of CYP450 activity became more pronounced with the increase in TP dosage.

\section{Verification in mRNA and protein level}

\section{Effect on TRNA expression of CYP3A and CYP2C9}

After oral administration of either the vehicle or TP (200, 400 or $600 \mu \mathrm{g} /(\mathrm{kg}$.day $))$ for 28 days, the mRNA levels of many CYP3A subfamily isoforms and CYP2C9 in TPtreated groups showed a significant decrease $(P<0.05$ or $P$ $<0.01)$ in comparison with that observed in the control group (Fig. 8a). The $200 \mu \mathrm{g} /(\mathrm{kg}$.day) TP group exhibited decreased CYP3A2 (49.8\%) and CYP3A62 (86.2\%), and 


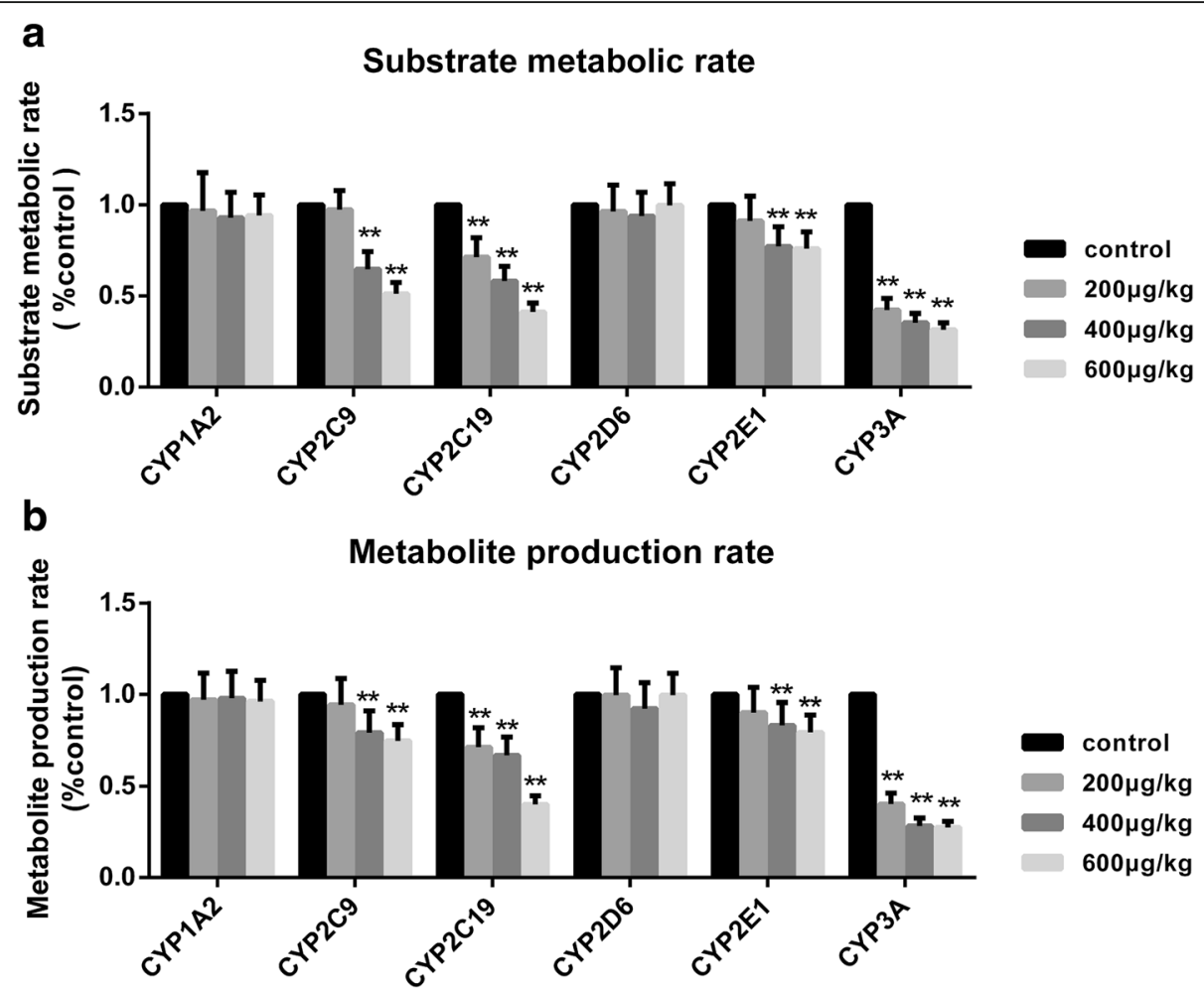

Fig. 6 Effects of TP on the CYP450s enzyme activity. a The effect of TP on the substrate metabolic rate. After orally treated with vehicle or 200, 400 or $600 \mu \mathrm{g} / \mathrm{kg} /$ day of triptolide for 28 days, the liver microsomes were incubated with the cocktail probe (CAF/D860/MT/DM/CLZ/MDZ: 15/20/ 10/10/5/2.5 $\mu \mathrm{M}$ ) for 30 mins. The final concentration of the substrates and metabolites were detected by UPLC-MS/MS. the substrate metabolic rate of CYP1A2, CYP2D6 after the 30-min-incubation in vitro remained the same but other CYP450s showed significant changes. The $200 \mu \mathrm{m} / \mathrm{kg} /$ day TP group exhibited decreases in CYP2C19 and CYP3A; then the 400 and $600 \mu \mathrm{g} / \mathrm{kg} / \mathrm{day}$ TP group exhibited decreases not only in CYP2C19 and CYP3A, but also CYP2E1 and CYP2C9. b The effect of TP on the production of the metabolites. After the administration, the $200 \mu \mathrm{g} / \mathrm{kg} / \mathrm{day}$ TP group showed decreases in CYP2C19 and CYP3A, then the 400 and $600 \mu \mathrm{g} / \mathrm{kg} /$ day TP group also exhibited decreases in CYP2E1 and CYP2C9. Results are expressed as mean \pm SD of each group, respectively; ${ }^{*}<0.05,{ }^{* *} P<0.01$ significantly different from the control group

increased CYP3A9 (1.17 fold) mRNA expression. The $400 \mu \mathrm{g} /(\mathrm{kg}$. day) TP group also exhibited decreased CYP3A2 (37.8\%), CYP3A62 (61.5\%), CYP3A1/3A23 (73.7\%), and CYP3A9 (84.8\%) mRNA expression. The $600 \mu \mathrm{g} /(\mathrm{kg}$. day) TP group exhibited a stronger decrease in CYP3A1/3A23 (61.8\%), CYP3A2 (23.2\%), CYP3A9 (60.6\%), and CYP3A62 (55.2\%) mRNA expression. Expression of CYP2C9 mRNA in the 200, 400, and $600 \mu \mathrm{g} /(\mathrm{kg}$.day) TP groups decreased in a dose-dependent manner to $72.3,66.3$, and $28.2 \%$, respectively, in comparison with that observed in the control.

\section{Effect on protein expression of CYP2C19 and CYP2E1}

When the effects of TP on CYP450 protein expression in rat liver microsomes were studied (Fig. 8b-c), TP was observed to decrease the protein expression of $\mathrm{CYP} 2 \mathrm{C} 19$ and CYP2E1 in a dose-dependent manner $(P<0.05$ or $P<0.01)$, in comparison to that observed in the control. The $600 \mu \mathrm{g} /$ (kg.day) TP group exhibited a particularly strong decrease in CYP2C19 (41.9\%) and CYP2E1 (51.4\%) protein expression.
Results of the immunohistochemical detection of CYP2C19 and CYP2E1 in rat liver sections were as shown in (Fig. 8d-e). TP was observed to decrease CYP2C19 and CYP2E1 expression in immunoreactive cells in a dose-dependent manner $(P<0.05$ or $P<0.01)$, in comparison to that observed in the control. The immunoreactive cells of the $600 \mu \mathrm{g} /(\mathrm{kg}$.day) TP group exhibited a particularly strong decrease in CYP2C19 (27.5\%) and CYP2E1 (38.2\%) expression.

\section{Discussion}

Based on pre-experimental observations, we found that TP-induced liver injury was more severe and stable in female rats than in male rats. Hence, female SD rats were specifically selected for this study. We found a certain correlation between the dosages of TP and hepatotoxicity in rats, which was consistent with previously published results $[7,21]$. The TP-treated groups exhibited histopathological changes. Additionally, changes in the biochemical indicators suggested that the mechanisms 


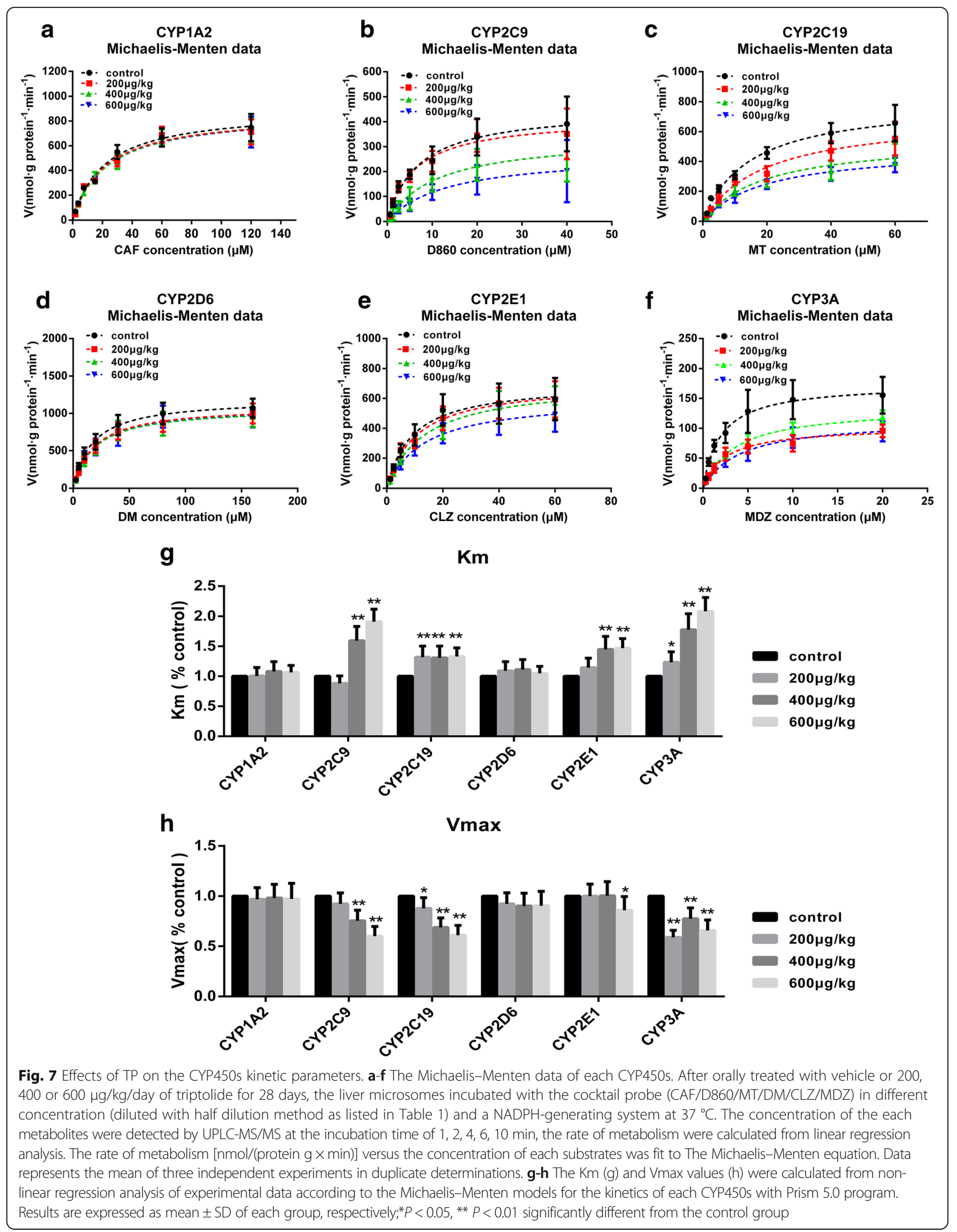




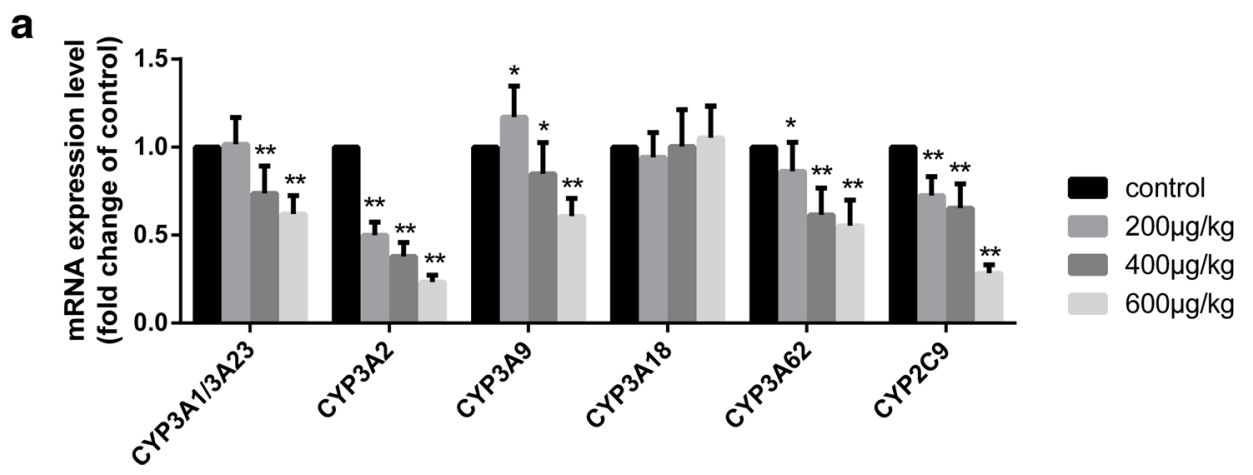

b
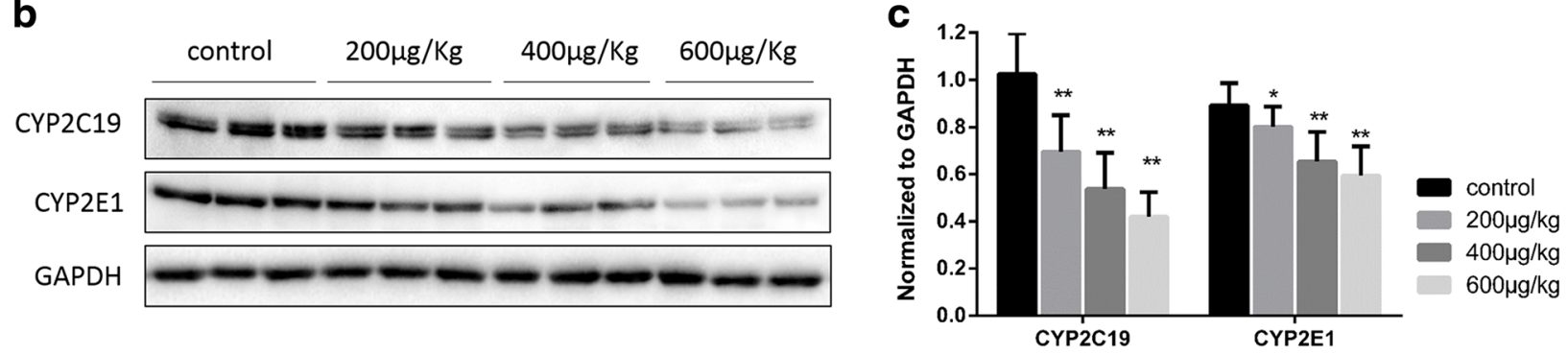

d

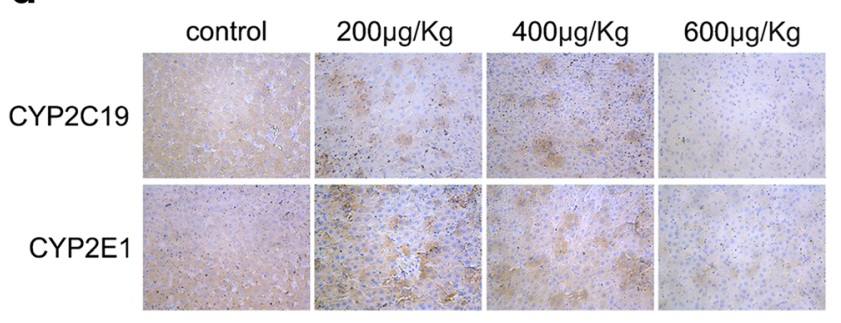

e

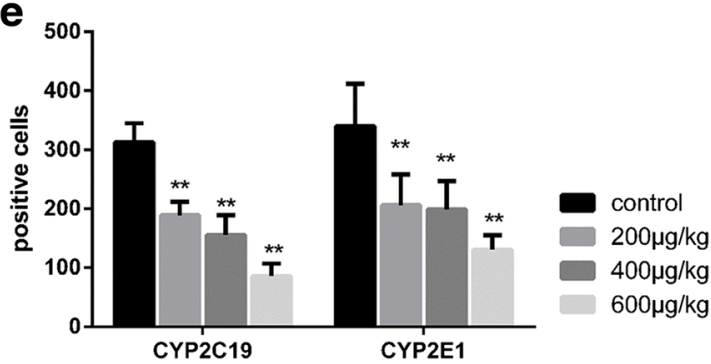

Fig. 8 Verification in mRNA and protein level. a Effect of triptolide on mRNA levels of CYP3A family and CYP2C9 in livers of rats. Liver lysates were made from livers of rats. $\mathbf{b}$ Protein lysates were made from microsomes of rats' liver and subjected to Western blot analysis using the indicated antibodies. The GAPDH was used as an internal control. A representative blot from three rats in each group was shown. The density of the immunoreactive bands was analyzed as(c). d Immunohistochemical detection of CYP2C19 and CYP2E1 in livers section of rats was shown. The Immunoreactive cells were stereo logically quantified (e). Symbols and bars represent the mean $\pm S D$, respectively; ${ }^{*} p<0.05$, ${ }^{* *} p<0.01$ versus the control group

of liver injury differed with different TP dosages and would be progressed by higher concentration.

An intensive understanding of the CYP450 dysregulation phenomenon in TP-induced liver injury is necessary because of its significance in guiding the drug dosage in patients who require the co-administration of other drugs with TP. As shown in Fig. 4, TP decreased the activities of CYP2C19, CYP2C9, CYP2E1 and the CYP3A subfamily without attenuating the liver microsomal protein concentration. CYP3A, which metabolizes $60 \%$ of all clinical drugs, is the most important enzyme for drug metabolism. In our study, the result about CYP3A confirmed its major role in the metabolism of TP. It should be noted that drugs which are metabolized by CYP3A should be avoided or reasonably adjusted when coadministered with TP or its related preparations, orally.
The metabolic activation of carcinogens and toxins is mainly mediated by CYP2E1 $[29,30]$, and drugs of the nervous system are mainly metabolized by the CYP2C subfamily [31, 32]. Clinicians should therefore closely monitor the patient's liver-related indices and adjust the medication when co-administering drugs which are mainly metabolized by these CYP450s along with TP to avoid toxic side effects.

In our study, we observed a TP dose-dependent decrease in the mRNA expression of most CYP3A subfamily isoforms and CYP2C9, which was consistent with the results of our metabolic study. Among the five main CYP3A isoforms in rats, the expression of CYP3A2 and CYP3A62 mRNAs was most sensitive to TP-induced toxicity. The expression of CYP3A1/3A23 and CYP3A9 mRNAs was also significantly decreased at higher TP 
dosages, while there was no such inhibitory effect on CYP3A18. This phenomenon may have been due to the use of adult rats in this experiment, as CYP3A18 expression is strongly correlated with growth hormone production [33]. CYP3A4 was reported to be primarily responsible for the hydroxylation of TP in the human liver [16]. In vitro studies of TP with CYP isoforms and P-glycoprotein (P-gp) indicate that TP has the potential to cause pharmacokinetic drug interactions when co-administered with other drugs metabolized by CYP1A2 and CYP3A4 [34]. As the major member of CYP3A subfamily in rats, CYP3A1/3A23 and CYP3A2 had $89 \%$ in their amino acid sequences [35], and CYP3A2 was reported to be specifically expressed in male rats [36]. In this study, we found that CYP3A2 played a very important role in the dysregulation of CYP450 activity due to TP-induced liver injury, in female rats as well. In spite of the sequence similarity, many functional differences exist between CYP3A1/3A23 and CYP3A2. [28]. In our study, while the mRNA expression pattern of CYP3A62 and CYP3A9 showed similar trends in the 400 and $600 \mu \mathrm{g} /(\mathrm{kg}$.day) TP groups, the trends were completely different in the $200 \mu \mathrm{g} /$ (kg.day) TP group. This phenomenon may have been due to the metabolic difference exhibited by different concentrations of TP and needs to be investigated further.

CYP2C9, an important component of the liver enzyme system, comprises about $10 \%$ of the total liver CYP450 enzyme content and is involved in the metabolism of $10 \%$ of the drugs in clinical trials [37]. In this study, we observed that CYP2C9 activity in the $200 \mu \mathrm{g} /$ (kg.day) TP group was not inhibited although its mRNA expression was significantly decreased, after the administration of TP for 28 days. But in the 400 and $600 \mu \mathrm{g} /(\mathrm{kg}$.day) TP groups, the enzyme affinity, activity, and mRNA expression of CYP2C9 were significantly decreased, thus confirming the dose-dependent inhibitory effect of TP on CYP2C9.

According to our results, the protein expression of CYP2C19 and CYP2E1 decreased in a TP dose-dependent manner, which was consistent with the results of our metabolic study. Besides the CYP3A subfamily, CYP2C19 is also reported to be involved in TP metabolism and toxicity $[16,34]$, and is therefore being actively researched. High doses of TP have been previously reported to significantly upregulate the levels of CYP2E1 mRNA in comparison with that observed in the control, after intragastric administration of TP $(0.05,0.3$ and $0.6 \mathrm{mg} /(\mathrm{kg}$.day $))$ for 7 consecutive days [38]. However, in our study, we observed a significant decrease in CYP2E1 enzyme affinity and activity in TP-treated groups, and the protein expression study further confirmed this inhibitory effect of TP. We speculate that the difference between our findings and those of the previous report [38] may be due to a difference in the time of intragastric administration of TP.
This experimental research demonstrated the abnormal metabolism of CYP450 enzyme system after TP administration. This results will hopefully serve as useful information for further understanding of the underlying mechanisms of TP-induced subacute toxicity. This results also suggests that when the patient needs to take TP for a certain time, doctors should pay attention to avoid the co-administration with drugs which metabolized by CYP3A, CYP2C9, CYP2C19, CYP2E1. If the co-administration was inevitable, doctors should closely observe the liver function.

There are several limitations in our work. First, the relationship between CYP450 dysregulation and TPinduced hepatotoxicity remains undefined because we did not determine the exact mechanism through which TP affects CYP450 activity. Second, although we observed the effect of different concentrations of TP on CYP450 activity, the effect of different times of drug administration still needs to be investigated. Finally, all our experiments were conducted in rat liver microsomes or tissues; therefore, the effects of TP on real patients need to be investigated in the future.

\section{Conclusions}

In summary, intragastric administration of TP (200, 400, and $600 \mu \mathrm{g} /(\mathrm{kg}$.day $))$ for 28 consecutive days can cause hepatotoxicity by reducing the substrate affinity, activity, and expression at the transcriptional and protein level of CYP3A, CYP2C9, CYP2C19, and CYP2E1. TP also has the potential to cause pharmacokinetic drug interactions when co-administered with drugs metabolized by these four CYP450 isoforms. However, further clinical studies are needed to evaluate the significance of this interaction.

\section{Additional files}

Additional file 1: Table S1. Effect of TP on Biochemical Indicators. (DOCX $14 \mathrm{~kb}$ )

Additional file 2: Table S2. Effects of TP on the CYP450s enzyme substrates and metabolites. (DOCX 16 kb)

Additional file 3: Table S3. Effects of TP on the CYP450s kinetic parameters. (DOCX 15 kb)

\section{Abbreviations}

ALB: Albumin; ALT: Alanine aminotransferase; AST: Aspartate aminotransferas; CAF: Caffeine; CLZ: Chlorzoxazone; CYP450s: Cytochrome P450 enzymes; D860: Tolbutamide; DDI: Drug-drug interaction; DM: Dextromethorphan; DTT: Dithiothreitol; DZP: Diazepam; EDTA: Ethylene Diamine Tetraacetic Acid; GLB: Globulin; Glu: Glucose; ISTD: Internal standard; MDZ: Midazolam; mRNA: Messenger Ribonucleic Acid; MT: (S)-Mephenytoin; PAGE: Polyacrylamidegel electrophoresis; PMSF: Phenylmethanesulfonyl fluoride; PVDF: Poly-vinylidene difluoride; RIPA: Radio immuno precipitation; RT-qPCR: Quantitative real-time polymerase chain reaction; SDS: Sodium dodecylsulphate; T-chol: Total cholesterol; TG: Triglycerides; TPT: riptolide; Tp: Total protein; TWHF: Tripterygium wilfordii Hook F; UPLC-MS/MS: Ultra performance liquid chromatographytandem mass spectrometry. 


\section{Acknowledgments}

We would like to thank Ms. Hongyan Long, the chief of the Central Laboratory of The Third Affiliated Hospital, Nanjing University of Chinese Medicine for providing experimental sites. We would also like to thank the members of Institute of TCM of Nanjing Chinse Medicine Hospital for their assistance with UHPLC-MS/MS study.

\section{Funding}

This study was financially supported by the Natural Science Foundation of China (Grants No. 81573869); the Natural Science Foundation of Jiangsu Province, China (Grant No. BK20130959; BK20140960); the Specialized Research Fund for the Doctoral Program of Higher Education of China (Grant No. 20133237120001)

\section{Availability of data and materials}

The datasets supporting this manuscript are included within the material and methods section of the article and also in the additional supporting information. These informations would be available for publication in the appropriate sections of this article.

\section{Authors' contributions}

Xueping Zhou and Tong Xie conceived and designed the experiments; Yan Lu, Yajie Zhang, Fuqiong Zhou, Jie Ruan, Weina Zhu, Zhe Feng performed the experiments; Huaxu Zhu provided the chemicals, and Yan Lu analyzed the data and wrote the paper. All authors read and approved the final manuscript.

\section{Competing interests}

The authors declare that they have no competing interests.

\section{Consent for publication}

All the authors listed in this manuscript have read and approved the final version for publication.

\section{Ethics approval and consent to participate}

All animal studies were performed with the approval of the Institutional Animal Care and Use Committee of Nanjing University of Chinese Medicine, and were performed according to the guidelines of the National Institutes of Health for the Care and Use of Laboratory Animals (NIH publication No. 80-23).

\section{Author details}

'The First Clinical College, Nanjing University of Chinese Medicine, Nanjing, Jiangsu, China. ${ }^{2}$ The Third Affiliated Hospital, Nanjing University of Chinese Medicine, Nanjing, Jiangsu, China. ${ }^{3}$ College of Pharmacy, Nanjing University of Chinese Medicine, Nanjing, Jiangsu, China.

\section{Received: 17 August 2016 Accepted: 9 December 2016}

\section{Published online: 05 January 2017}

\section{References}

1. Kupchan SM, Court WA, Dailey Jr RG, Gilmore CJ, Bryan RF. Triptolide and tripdiolide, novel antileukemic diterpenoid triepoxides from Tripterygium wilfordii. J Am Chem Soc. 1972;94(20):7194-5.

2. Qiu D, Kao PN. Immunosuppressive and anti-inflammatory mechanisms of triptolide, the principal active diterpenoid from the Chinese medicinal herb tripterygium wilfordii hook. f. Drugs R D. 2003;4(1):1-18.

3. Shamon LA, Pezzuto JM, Graves JM, Mehta RR, Wangcharoentrakul S, Sangsuwan R, Chaichana S, Tuchinda P, Cleason P, Reutrakul V. Evaluation of the mutagenic, cytotoxic, and antitumor potential of triptolide, a highly oxygenated diterpene isolated from tripterygium wilfordii. Cancer Lett. 1997;112(1):113-7.

4. Zheng Y, Zhang WJ, Wang XM. Triptolide with potential medicinal value for diseases of the central nervous system. CNS Neurosci Ther. 2013;19(2):76-82.

5. Ziaei S, Halaby R. Immunosuppressive, anti-inflammatory and anti-cancer properties of triptolide: a mini review. Avicenna j phytomedicine. 2016;6(2):149-64.

6. Cao Y, Huang X, Fan Y, Chen X. Protective effect of triptolide against glomerular mesangial cell proliferation and glomerular fibrosis in rats involves the TGF- beta 1/smad signaling pathway. Evid Based Complement Alternative Med. 2015;2015:814089.
7. Li XJ, Jiang ZZ, Zhang LY. Triptolide: progress on research in pharmacodynamics and toxicology. J Ethnopharmacol. 2014;155(1):67-79.

8. Yao J, Jiang Z, Duan W, Huang J, Zhang L, Hu L, He L, Li F, Xiao Y, Shu $B$, et al. Involvement of mitochondrial pathway in triptolideinduced cytotoxicity in human normal liver L-02 cells. Biol Pharm Bull. 2008:31(4):592-7.

9. Cao LJ, Li HD, Yan M, Li ZH, Gong H, Jiang P, Deng Y, Fang PF, Zhang BK. The protective effects of isoliquiritigenin and glycyrrhetinic acid against triptolide-induced oxidative stress in HepG2 cells involve Nrf2 activation. Evid Based Complement Alternat Med. 2016;2016:8912184.

10. Srivastava A, Maggs $J$ L, Antoine DJ, Williams DP, Smith DA, Park BK. Role of reactive metabolites in drug-induced hepatotoxicity. Handb Exp Pharmacol. 2010;196:165-94.

11. Nebert DW, Russell DW. Clinical importance of the cytochromes P450. Lancet. 2002:360(9340):1155-62.

12. Testa B, Pedretti A, Vistoli G. Reactions and enzymes in the metabolism of drugs and other xenobiotics. Drug Discov Today. 2012;17(11-12):549-60.

13. Du F, Liu Z, Li X, Xing J. Metabolic pathways leading to detoxification of triptolide, a major active component of the herbal medicine tripterygium wilfordii. J Appl Toxicol. 2014;34(8):878-84.

14. Zhuang XM, Shen GL, Xiao WB, Tan Y, Lu C, Li H. Assessment of the roles of P-glycoprotein and cytochrome P450 in triptolide-induced liver toxicity in sandwich-cultured rat hepatocyte model. Drug Metab Dispos. 2013;41(12):2158-65.

15. Shao F, Wang G, Xie H, Zhu X, Sun J, A J. Pharmacokinetic study of triptolide, a constituent of immunosuppressive chinese herb medicine, in rats. Biological \& pharmaceutical bulletin.2007.30(4).702-707.

16. Li W, Liu Y, He YQ, Zhang JW, Gao Y, Ge GB, Liu HX, Huo H, Liu HT, Wang $L M$, et al. Characterization of triptolide hydroxylation by cytochrome P450 in human and rat liver microsomes. Xenobiotica. 2008;38(12):1551-65.

17. Ye X, Li W, Yan Y, Mao C, Cai R, Xu H, Yang X. Effects of cytochrome P4503A inducer dexamethasone on the metabolism and toxicity of triptolide in rat. Toxicol Lett. 2010;192(2):212-20.

18. Zhang XF, Liu J, Ye F, Ji SG, Zhang N, Cao RS, He L, Wu JC, Li XF. Effects of triptolide on the pharmacokinetics of cyclophosphamide in rats: a possible role of cytochrome P3A4 inhibition. Chin J Integr Med. 2014;20(7):534-9.

19. Shen G, Zhuang X, Xiao W, Kong L, Tan Y, Li H. Role of CYP3A in regulating hepatic clearance and hepatotoxicity of triptolide in rat liver microsomes and sandwich-cultured hepatocytes. Food Cheml Toxicol. 2014;71:90-6.

20. Frye RF. Probing the world of cytochrome P450 enzymes. Mol Interv. 2004;4(3):157-62.

21. Liu L, Jiang Z, Liu J, Huang X, Wang T, Liu J, Zhang Y, Zhou Z, Guo J, Yang $L$, et al. Sex differences in subacute toxicity and hepatic microsomal metabolism of triptolide in rats. Toxicology. 2010;271(1-2):57-63.

22. von Bahr C, Groth CG, Jansson H, Lundgren G, Lind M, Glaumann H. Drug metabolism in human liver in vitro: establishment of a human liver bank. Clin Pharmacol Ther. 1980;27(6):711-25.

23. Omura T, Sato R. The carbon monoxide-binding pigment of liver microsomes. li. Solubilization, purification, and properties. J Biol Chem. 1964;239:2379-85.

24. Spaggiari D, Geiser L, Daali Y, Rudaz S. A cocktail approach for assessing the in vitro activity of human cytochrome P450s: an overview of current methodologies. J Pharm Biomed Anal. 2014;101:221-37.

25. Mahnke A, Strotkamp D, Roos PH, Hanstein WG, Chabot GG, Nef P. Expression and inducibility of cytochrome P450 3A9 (CYP3A9) and other members of the CYP3A subfamily in rat liver. Arch Biochem Biophys. 1997;337(1):62-8.

26. Nagata K, Murayama N, Miyata M, Shimada M, Urahashi A, Yamazoe Y, Kato $R$. Isolation and characterization of a new rat P450 (CYP3A18) CDNA encoding P450(6)beta-2 catalyzing testosterone 6 beta- and 16 alphahydroxylations. Pharmacogenetics. 1996;6(1):103-11.

27. Kirita S, Matsubara T. cDNA cloning and characterization of a novel member of steroid-induced cytochrome P450 3A in rats. Arch Biochem Biophys. 1993;307(2):253-8.

28. Matsubara T, Kim HJ, Miyata M, Shimada M, Nagata K, Yamazoe Y. Isolation and characterization of a new major intestinal CYP3A form, CYP3A62, in the rat. J Pharmacol Exp Ther. 2004;309(3):1282-90.

29. Martinez-Gil N, Flores-Bellver M, Atienzar-Aroca S, Lopez-Malo D, Urdaneta AC, Sancho-Pelluz J, Peris-Martinez C, Bonet-Ponce L Romero FJ, Barcia JM. CYP2E1 in the human retinal pigment epithelium: expression, activity, and induction by ethanol. Invest Ophthalmol Vis Sci. 2015;56(11):6855-63. 
30. Hartman JH, Martin HC, Caro AA, Pearce AR, Miller GP. Subcellular localization of rat CYP2E1 impacts metabolic efficiency toward common substrates. Toxicology. 2015;338:47-58.

31. Lewis DF, Ito Y, Goldfarb PS. Investigating human P450s involved in drug metabolism via homology with high-resolution P450 crystal structures of the CYP2C subfamily. Curr Drug Metab. 2006;7(6):589-98.

32. Booth Depaz IM, Toselli F, Wilce PA, Gillam EM. Differential expression of cytochrome P450 enzymes from the CYP2C subfamily in the human brain. Drug Metab Dispos. 2015;43(3):353-7.

33. Kawai M, Bandiera SM, Chang TK, Bellward GD. Growth hormone regulation and developmental expression of rat hepatic CYP3A18, CYP3A9, and CYP3A2. Biochem Pharmacol. 2000;59(10):1277-87.

34. Zhang H, Ya G, Rui H. Inhibitory effects of triptolide on human liver cytochrome P450 enzymes and P-glycoprotein. Eur J Drug Metab Pharmacokinet. 2016

35. Nelson DR, Kamataki T, Waxman DJ, Guengerich FP, Estabrook RW Feyereisen R, Gonzalez FJ, Coon MJ, Gunsalus IC, Gotoh O, et al. The P450 superfamily: update on new sequences, gene mapping, accession numbers, early trivial names of enzymes, and nomenclature. DNA Cell Biol. 1993;12(1):1-51.

36. Cooper KO, Reik LM, Jayyosi Z, Bandiera S, Kelley M, Ryan DE, Daniel R, McCluskey SA, Levin W, Thomas PE. Regulation of two members of the steroid-inducible cytochrome P450 subfamily (3A) in rats. Arch Biochem Biophys. 1993;301(2):345-54.

37. Takeuchi M, Kobayashi T, Brandao LR, Ito S. Effect of CYP2C9, VKORC1, and CYP4F2 polymorphisms on warfarin maintenance dose in children aged less than 18 years: a protocol for systematic review and meta-analysis. Syst Rev. 2016;5(1):105.

38. Han FM, Peng ZH, Wang JJ, Chen Y. In vivo effect of triptolide combined with glycyrrhetinic acid on rat cytochrome P450 enzymes. Yao xue xue bao = Acta Pharma Sin. 2013;48(7):1136-41.

\section{Submit your next manuscript to BioMed Central and we will help you at every step:}

- We accept pre-submission inquiries

- Our selector tool helps you to find the most relevant journal

- We provide round the clock customer support

- Convenient online submission

- Thorough peer review

- Inclusion in PubMed and all major indexing services

- Maximum visibility for your research

Submit your manuscript at www.biomedcentral.com/submit 